(2) Open Access Full Text Article

REVIEW

\title{
Amyotrophic lateral sclerosis and the clinical potential of dexpramipexole
}

\author{
This article was published in the following Dove Press journal: \\ Therapeutics and Clinical Risk Management \\ 24 August 2012 \\ Number of times this article has been viewed
}

\author{
Philippe Corcia' \\ Paul H Gordon ${ }^{2}$ \\ 'Centre SLA, CHRU de Tours, \\ Tours, France; UMR INSERM U930, \\ Université François Rabelais de Tours \\ (PC), Tours, France; ${ }^{2}$ AP-HP, Hôpital de \\ la Pitié-Salpêtrière, Département des \\ Maladies du Système Nerveux (PHG), \\ Paris, France
}

Correspondence: Paul H Gordon Fédération des Maladies du Système Nerveux, Centre référent maladie rare SLA, Hôpital de la Pitié-Salpêtrière, 47-83, Boulevard de I'Hôpital, 7565I Paris, France

Email paul.gordon@psl.aphp.fr

\begin{abstract}
Amyotrophic lateral sclerosis (ALS) is a neurodegenerative disorder that leads to progressive weakness from loss of motor neurons and death on average in less than 3 years after symptom onset. No clear causes have been found and just one medication, riluzole, extends survival. Researchers have identified some of the cellular processes that occur after disease onset, including mitochondrial dysfunction, protein aggregation, oxidative stress, excitotoxicity, inflammation, and apoptosis. Mitochondrial disease may be a primary event in neurodegeneration or occur secondary to other cellular processes, and may itself contribute to oxidative stress, excitotoxicity, and apoptosis. Clinical trials currently aim to slow disease progression by testing drugs that impact one or more of these pathways. While every agent tested in the 18 years after the approval of riluzole has been ineffective, basic and clinical research methods in ALS have become dramatically more sophisticated. Dexpramipexole (RPPX), the R(+) enantiomer of pramiprexole, which is approved for symptomatic treatment of Parkinson disease, carries perhaps the currently largest body of pre- and early clinical data that support testing in ALS. The neuroprotective properties of RPPX in various models of neurodegeneration, including the ALS murine model, may be produced through protective actions on mitochondria. Early phase trials in human ALS suggest that the drug can be taken safely by patients in doses that provide neuroprotection in preclinical models. A Phase III trial to test the efficacy of RPPX in ALS is underway.
\end{abstract}

Keywords: dexpramipexole, amyotrophic lateral sclerosis, survival, clinical trials, neurodegeneration

\section{Introduction}

Amyotrophic lateral sclerosis (ALS) is the third most common neurodegenerative disorder in developed countries, ${ }^{1}$ with an estimated worldwide incidence of $1.2-4.0 / 100,000$ people. $^{2-6}$ The illness is characterized by progressive degeneration of upper and lower motor neurons in bulbar as well as spinal myotomes. The result for patients is progressive weakness of voluntary muscles that can lead to complete paralysis. Cognition is impaired in $20 \%-50 \%$ of patients who undergo neuropsychological testing, and 5\%-15\% of ALS patients develop overt frontotemporal dementia. ${ }^{7,8}$ Oculomotor, sphincter, and extrapyramidal function are spared in the majority of patients. Two major clinical forms, bulbar and spinal ALS, are described based on the site-of-onset of motor weakness. The two phenotypes are associated with a particular sex predominance, age-of-onset, and disease duration. Limb-onset disease, which makes up about $75 \%$ of ALS, predominates in men, while bulbar-onset cases are more frequent in women and the elderly, and have shorter survival. ${ }^{9}$ Rarely, ALS begins in 
respiratory myotomes, which carries the poorest prognosis. ${ }^{10}$ The mechanisms underlying the different sites-of-onset are just beginning to be explored. ${ }^{11}$

The disease is almost always fatal, with a median survival time of 30 months from onset and 19 months from diagnosis, ${ }^{12}$ but some patients live just a few months while others survive for several decades. Death is usually, but not invariably, caused by respiratory failure. ${ }^{13,14}$

A principal difficulty in the diagnosis and management of ALS is the absence of biomarkers, which contributes to a diagnostic delay of 9-12 months and to initial false-negative diagnosis in up to $10 \%$ of cases. ${ }^{15}$ Electromyography aids the diagnosis, and laboratory assessments as well as neuroimaging help exclude alternative diagnoses, including compressive cervical myelopathy or multifocal motor neuropathy, among others. ${ }^{15,16}$ Ultimately, the diagnosis of ALS is based on the identification of progressive upper and lower motor neuron signs by history and examination. To aid in standardizing enrollment in clinical research studies, diagnostic criteria were developed in 1994, revised in 1998, and revised again in 2006 on Awaji-Shima Island. ${ }^{17,18}$ Four stages of diagnostic certainty are defined as clinically definite or probable, laboratory-supported probable, and clinically possible based on the number of affected regions (bulbar, cervical, thoracic, and lumbosacral). ${ }^{17}$ The consensus meeting in Awaji-Shima Island modified the electromyographic criteria, equating electromyographic abnormalities with clinical findings and restoring the diagnostic importance of fasciculation potentials to that of fibrillation potentials. ${ }^{18}$ The modified criteria may improve diagnostic sensitivity in patients with bulbar-onset or upper motor neuron predominant disease. ${ }^{19}$

\section{Pathogenesis}

ALS is thought to be a complex genetic disorder in which genetic and environmental risk factors combine in the pathogenesis, but cigarette smoking is the only universally accepted environmental risk factor, ${ }^{20}$ and no genes have been consistently identified that contribute to sporadic ALS. While $85 \%-90 \%$ of ALS is sporadic, the remaining familial cases are usually inherited in an autosomal dominant pattern. ${ }^{21}$ During the past 20 years, numerous genes and loci have been linked to familial ALS (Table 1). The most frequently identified gene to date is the $c 9$ orf 72 gene, which is involved in approximately $40 \%$ of familial cases. ${ }^{21}$ Mutations in the superoxide dismutase (SOD1) gene, the first identified in ALS, cause between $5 \%$ and $10 \%$ of familial ALS and were used in the advent of an important rodent model of the disease. ${ }^{22}$ Increasing numbers of mutated genes are being
Table I Genes mutated in familial ALS

\begin{tabular}{llll}
\hline Locus & Gene & Inheritance & Phenotype \\
\hline ALSI & SODI & AD, AR & ALS, PMA \\
ALS2 & ALS2 & AR & Juvenile ALS, Juvenile PLS \\
ALS3 & Not defined & AD & ALS \\
ALS4 & SETX & AD & ALS, dHMN \\
ALS5 & SPGII & AR & Juvenile ALS \\
ALS6 & FUS & AD, AR, De Novo & ALS, ALS-FTD \\
ALS7 & Not defined & AD & ALS \\
ALS8 & VAPB & AD & ALS, PMA \\
ALS9 & ANG & AD & ALS, ALS-FTD, PBP \\
ALSI0 & TARDBP & AD & ALS, ALS-FTD \\
ALSII & FIG4 & AD & ALS, PLS \\
ALSI2 & OPTN & AD, AR & ALS \\
ALSI3 & ATXN2 & AD & ALS \\
& C9orf2 & AD & ALS, FTD, ALS-FTD \\
\hline
\end{tabular}

Abbreviations: ALS, amyotrophic lateral sclerosis; PLS, primary lateral sclerosis; PMA, progressive muscular atrophy; FTD, frontotemporal dementia; dHMN, distal hereditary motor neuropathy; PBP, progressive bulbar palsy; AD, autosomal dominant; AR, autosomal recessive.

described in ALS, but the mechanisms underlying their contribution to the disorder await elucidation. ${ }^{21}$

\section{Pathophysiology}

While the causes for most ALS are still mysterious, more is known from human and animal studies about the cellular events that transpire after disease onset. ${ }^{23,24}$ Excitotoxicity, protein aggregation, oxidative stress due to free radical production, abnormal axonal transport, poor RNA function, mishandling of glutamate by glial cells, mitochondrial dysfunction, inflammation and apoptosis all appear to play a role in cell death in ALS. ${ }^{24}$ The timing and sequence of the different mechanisms have proved more difficult to explore. ${ }^{25}$ A central theme in many of the pathways is the role of mitochondrial impairment. ${ }^{26}$

Mitochondria are the major source of cellular energy. They are enveloped by two membranes, separated by an intermembrane space. The mitochondrial respiratory chain is located in the inner membrane and consists of four complexes that manage the reduction-oxidation reactions that transfer electrons from one complex to another. Complex IV, cytochrome c oxidase, transfers electrons to molecular oxygen, creating water, and in the process helps to generate the transmembrane electrochemical gradient that drives adenosine triphosphate (ATP) production. Other roles have recently been attributed to mitochondria such as buffering intracellular calcium and triggering apoptotosis. ${ }^{27}$

Because mitochondria play a critical role in all energetic processes in motor neurons, which are the largest nerve cells and whose metabolism requires the greatest energetic supply, 
mitochondrial integrity appears crucial for motor neuron viability. Mitochondrial dysfunction could be a primary or secondary event in motor neuron cell death. Evidence for mitochondrial impairment in ALS first came over 40 years ago from microscopic studies that revealed abnormal mitochondrial structural morphology. ${ }^{28}$ Later, alterations of the mitochondrial machinery were shown through research that described an increase in mitochondrial activity in the frontal cortex of ALS patients carrying the SOD1 mutation. ${ }^{29}$ Numerous disturbances of mitochondrial function have subsequently been implicated in the pathophysiology of ALS, from oxidative stress to glutamate-mediated excitotoxicity, promoting an increase of intracellular calcium and reduced calcium-buffering capacity. ${ }^{30}$ All of these events, including excitotoxicity, increased oxidative stress and activation of proapoptotic enzymes, could, in theory, stem from a single mitochondrial event, the formation of the mitochondrial permeability transition pore, which depletes the mitochondrial membrane potential, reducing generation of ATP. Mitochondrial impairment, excitotoxicity, and oxidative stress are linked because excess glutamate, increased intracellular calcium and failure to reduce free radical production are interrelated. ${ }^{31}$ Mitochondrial dysfunction and poor energy production are thought to eventually lead to motor neuron death through apoptosis..$^{27,32}$

\section{Management}

There is no cure yet for ALS, in no small part because the causes are elusive. Riluzole, the only drug approved so far for the treatment of ALS, extends survival without effect on motor function. ${ }^{33,34}$ The gain in survival, statistically significant in repeated studies, ${ }^{35}$ is approximately $11 \%$ or 3 months. ${ }^{36}$ The precise action of riluzole, a benzothiazole derivative, is unknown. ${ }^{25}$ The drug is a low-potency and nonspecific modulator of many pharmaceutical targets, including the inhibition of presynaptic glutamate release, originally thought to be the mechanism of action in ALS. However, other functions have been identified, including inactivation of voltage-dependent ion channels and prevention of protein aggregation, ${ }^{25,37}$ and other drugs with antiglutamate properties are ineffective in ALS. Currently, the final common pathway is thought to rely on modulation of motor neuron excitotoxicity. ${ }^{37,38}$ Blockade of voltage-dependent ion channels could represent a major mode of this action since riluzole improves survival without an effect on muscular function and increases feelings of asthenia (a frequent side effect). ${ }^{38}$

Until there is a curative treatment, most large centers manage symptoms to the extent possible using multidisciplinary clinics, which contribute to longer survival and better quality of life for patients. ${ }^{15,39}$ Evaluations of nutritional and respiratory status are key components of the multidisciplinary approach to care. Non-invasive ventilation and supplemental feedings may improve quality of life and survival if introduced early enough in the disease course. ${ }^{40-42}$

Continuing research for new and stronger agents is also a major thrust of ALS centers. More effective symptomatic and life-extending treatments of all types are badly needed and participation in research offers hope to patients. ${ }^{43}$ When really effective treatments are found, the successes will stand on the shoulders of all the research, including the participants, that preceded it.

Numerous clinical trials testing agents that target known mechanisms in the pathophysiology of motor neurons have been conducted during the last 18 years (Table 2). The benefit of riluzole led investigators to examine other agents with antiglutamatergic properties, but several trials showed no benefit, ${ }^{44,45}$ and trials of protein-clearing agents, ${ }^{46-49}$ antiinflammatory agents, ${ }^{50,51}$ antiapoptotic agents ${ }^{52}$ and immune modulators $^{53}$ were also negative. Use of different types and different approaches to administration of stem cells are being tried, but no efficacy has been demonstrated to date. ${ }^{35}$

Several problems currently face ALS researchers. First, the etiologies of ALS are still unknown, so it is not yet possible to target primary disease mechanisms. The rodent model, developed using an overexpression of the human mutated SOD-1 gene, has become a major source of drug screening, but many of the negative trials in humans have followed positive studies in the ALS model. These discordant findings have raised questions about the utility of the rodent models and support the need for the development of other models based on different genes. Consensus criteria are now published on the use of the $S O D-1$ model to standardize drug testing in rodents, ${ }^{54}$ and additional models using TARDBP or FUS mutated genes are under development. In addition, the absence of biomarkers means that therapeutic trials rely on clinical endpoints, which have high inter-individual variability, rendering trials long, large and expensive in order to detect meaningful changes in outcome measures. Finally, the disease is rare and rapidly progressive so that entering and maintaining patients in large trials has been problematic. Trial methodology is being refined, ${ }^{47,55-57}$ but truly meaningful treatment in ALS remains a matter of continued research for more effective molecules.

\section{Dexpramipexole}

Considering the potential central role of mitochondrial impairment in motor neuron death, neuroprotection through 
Table 2 Recent clinical trials in ALS

\begin{tabular}{|c|c|c|c|c|c|}
\hline Drug & Trial design & Mechanism & Sample & Endpoint & Outcome \\
\hline Glatiramer & Phase III & Immune modulator & 360 & ALSFRS-R & Negative \\
\hline Lithium & Phase II & $\begin{array}{l}\text { Antiglutamatergic, } \\
\text { Protein clearance }\end{array}$ & Up to $|7|$ & Survival/ALSFRS-R & Negative \\
\hline Ceftriaxone & Phase II-III & Antiglutamatergic & 600 & Survival/ALSFRS-R & Ongoing \\
\hline Memantine & Phase II & Antiglutamatergic & 63 & ALSFRS-R & Negative \\
\hline Arimoclomol & Phase II & Heat shock protein inducer & 84 & Safety & Adequate safety \\
\hline Talampanel & Phase II & Antiglutamatergic & 59 & Arm strength & $\begin{array}{l}\text { Nonsignificant } \\
\text { improvement }\end{array}$ \\
\hline CoQI0 & $\begin{array}{l}\text { Phase II dose } \\
\text { selection/futility }\end{array}$ & $\begin{array}{l}\text { Antioxidant/mitochondrial } \\
\text { cofactor }\end{array}$ & 185 & ALSFRS-R & Negative \\
\hline Minocycline & Phase III & Anti-inflammatory/antiapoptotic & 412 & ALSFRS-R & Negative \\
\hline Xaliproden & Phase III & Antiapoptotic & Up to 1210 & $\begin{array}{l}\text { Survival } \\
\text { Breathing capacity }\end{array}$ & Negative \\
\hline Gabapentin & Phase III & Antiglutamatergic & 204 & Arm strength & Negative \\
\hline Celecoxib & Phase III & Anti-inflammatory & 300 & Arm strength & Negative \\
\hline Riluzole & Phase III & Antiglutamatergic, unknown & Up to 959 & Survival & Positive \\
\hline
\end{tabular}

Abbreviation: ALSFRS-R, revised version of the Amyotrophic Lateral Sclerosis Functional Rating Scale.

maintenance of normally functioning mitochondria is one promising therapeutic avenue in ALS.

Perhaps the best researched agent currently under study is the mitochondrial protector pramipexole (PPX). ${ }^{58}$ The $\mathrm{S}(-)$ enantiomer of PPX, a nonergot dopamine analog that possesses D2, D3, and D4 autoreceptor agonist activity, is approved for the treatment of Parkinson disease and restless legs syndrome..$^{59,60}$ PPX, like riluzole, belongs to the benzothiazole family that has neuroprotective properties in models of acute and chronic neurodegeneration. ${ }^{61}$ The neuroprotective properties of PPX have been at the core of numerous recent studies, primarily in models of Parkinson disease, where PPX appears to exert its neuroprotective effects through actions on mitochondria ${ }^{62,63}$ and reducing activation of proapoptotic pathways. ${ }^{62-64}$ In rats treated with 3-AP, a nicotinamide antagonist, PPX exhibits stronger effects than riluzole against neurodegeneration. ${ }^{62}$ Glutamate-induced dopaminergic neuronal death is blocked by adding PPX to the culture medium, and continuous subcutaneous injection of PPX in rats inhibits the formation of ubiquitinated inclusions in dopaminergic neurons subjected to pro-inflammatory molecules. ${ }^{65,66}$ PPX protects dopamine neurons exposed to hypoxic damage, ${ }^{67}$ methamphetamine poisoning, 1-methyl-4- phenyl-1,2,3,6tetrahydro pyridine toxicity, ${ }^{68}$ and oxidative stress. ${ }^{68,69} \mathrm{PPX}$ scavenges free radicals in in vivo and in vitro models. ${ }^{63} \mathrm{In}$ humans, 12 ALS patients showed reduced measures of free radical production after receiving PPX in $6 \mathrm{mg} /$ day doses. ${ }^{70}$

Dexpramipexole (RPPX; KNS-760704 [Knopp Neurosciences, Pittsburgh, PA]; (6R)-4,5,6,7-tetrahydro-N6-propyl-2,6-benzothiazole-diamine), the $\mathrm{R}(+)$ enantiomer of PPX, was chosen for study in ALS because of greater tolerability at high doses than PPX..$^{32,71}$ The in-vivo neuroprotective effects of PPX require higher doses than can be tolerated in humans because of its high affinity for dopamine receptors, leading to dose-limiting side effects such as hypotension and hallucinations; side effects that have prevented the use of PPX as a neuroprotective agent in humans.

RPPX has a melting point between $285^{\circ} \mathrm{C}$ and $287^{\circ} \mathrm{C}$, and is highly water soluble $(>600 \mathrm{mg} / \mathrm{mL}) .{ }^{71}$ It is stable in solution in water and physiological buffer solutions, and is not hygroscopic. RPPX is moderately bound to human plasma proteins (40.3\%). Entry into the CNS is efficient with a brain-to-plasma ratio from 5 to 15 , depending on species and dose. The product is rapidly and essentially completely absorbed when dosed orally and its half-life ranges from 3-8 hours across species.

RPPX has similar neuroprotective properties to PPX, but lacks dopaminergic effects. When RPPX has more than $99 \%$ chiral and enantiomeric purity, it is essentially devoid of dopamine agonist side effects; the affinity of RPPX for D2, D3, and D4 receptors is less than 1000-fold lower than PPX. Thus, the major advantage of RPPX for neurodegenerative disorders is a lower affinity for dopaminergic receptors than PPX, allowing dose escalation into the ranges necessary for reaching a neuroprotective effect, while having greater tolerability. For this reason, RPPX was chosen instead of PPX as a potentially promising drug for trials in ALS. ${ }^{32,71}$

Like PPX, dexpramipexole reduces free radical production and neuronal cell death in models of oxidative stress, ${ }^{72,73}$ and reduces apoptosis. ${ }^{74-76}$ Dexpramipexole appears to exert neuroprotective effects by acting directly on mitochondria to stabilize ion conductances and maintain the gradients needed for ATP production. ${ }^{77}$ In several cell culture 
experiments, including neurons, dexpramipexole normalized the metabolism of injured cells and was protective against proteasome inhibition, apparently through maintenance of oxidative phosphorylation in the mitochondria. ${ }^{77}$ In models of parkinsonism, cells incubated with RPPX showed reduced markers of oxidative stress and were less susceptible to excitotoxicity. ${ }^{71}$ In transgenic ALS mice, $100 \mathrm{mg} /$ day of RPPX extended survival by approximately $5.6 \%$ and slowed motor decline compared to controls $(P=0.011){ }^{75}$

\section{Dexpramipexole in ALS}

Acute and chronic toxicology studies performed in animals were the preliminary steps in testing RPPX for human ALS. ${ }^{71}$ The no-observed adverse-effect-level (NOAEL) in rats of $100 \mathrm{mg} / \mathrm{kg}$ for males and $\geq 300 \mathrm{mg} / \mathrm{kg}$ in females after 6 months of dosing provided approximately 7 and 25 times the highest dose planned in clinical studies (300 mg), respectively. In minipigs, the NOAEL of $50 \mathrm{mg} / \mathrm{kg}$ after 9 months of dosing provided 10 to 15 times the $300 \mathrm{mg}$ human dose. ${ }^{71,74,76}$

The first clinical trials (Table 3 ) showed that RPPX was initially safe and well tolerated in humans. ${ }^{38}$ Two Phase I randomized, placebo-controlled, double blind safety trials were conducted in 54 healthy subjects. ${ }^{38}$ The safety and pharmacokinetic profile of PPX was evaluated in two trials that assessed a single dose of up to $300 \mathrm{mg}$ or multiple doses twice daily over 4.5 days. The trials were conducted sequentially. In the first study, subjects were enrolled to receive $50 \mathrm{mg}, 150 \mathrm{mg}, 300 \mathrm{mg}$, or placebo. In the second study, patients received twice-daily doses of up to $300 \mathrm{mg}$ /day or placebo. In both trials, pharmacokinetic profiles showed rapid absorption, with linear pharmacokinetics, and serum half-life of 6.4-8.1 hours. Almost all the drug was renally eliminated and food did not affect the absorption or elimination. No serious adverse events occurred in either study. Dizziness and headache were the most frequently reported adverse events overall. There were no dose effects on vital signs, electrocardiogram, or laboratory data. Together, these studies showed that much higher dosages of RPPX could be tolerated by people than is the case for PPX. ${ }^{38}$

A series of Phase II trials were designed for the next step of testing safety and obtaining early indications of possible efficacy in ALS patients. First, a 9-month 'futility' trial in 30 ALS patients treated with $30 \mathrm{mg}$ /day for 6 months following a 3-month lead-in phase compared pre- and posttreatment rates of progression. ${ }^{78}$ The drug was reported as safe and well tolerated. The trial had power to detect a $40 \%$ difference in decline; there was a nonsignificant $13 \%$ reduction in the decline in slope of the ALSFRS-R scale. Patients who completed the entire 9 month trial had a reduction in slope that reached $16 \%$ (also nonsignificant). ${ }^{78}$

A dose escalation study was then performed in a sample of 10 patients with definite or probable ALS. ${ }^{78}$ The initial dosage was $30 \mathrm{mg}$ /day with a weekly twofold increase until reaching $300 \mathrm{mg} /$ day for 2 weeks. The dose escalation was safe and well tolerated without any dopaminergic side effects. This trial was extended to a comparison of two dosages: $30 \mathrm{mg} /$ day vs $60 \mathrm{mg}$ /day over 6 months, with continued report of good safety. The slope of progression of the ALSFRS-R was nonsignificantly lower in the $60 \mathrm{mg}$ /day group compared to the $30 \mathrm{mg}$ /day group. ${ }^{78}$

Overall, these open-label trials enrolled a total sample of approximately 40 patients who received single and multiple doses of RPPX. Safety analyses, the most useful data from

Table 3 Trials of dexpramipexole in ALS

\begin{tabular}{|c|c|c|c|c|}
\hline Design & $\begin{array}{l}\text { Sample } \\
\text { size }\end{array}$ & $\begin{array}{l}\text { Primary } \\
\text { endpoints }\end{array}$ & $\begin{array}{l}\text { Secondary } \\
\text { endpoints }\end{array}$ & Outcome \\
\hline $\begin{array}{l}\text { Phase I randomized controlled } \\
\text { trials (single dose, then multidose) }\end{array}$ & 54 & $\begin{array}{l}\text { Safety and } \\
\text { pharmacokinetics }\end{array}$ & & Safe, well-tolerated, linear PK \\
\hline $\begin{array}{l}\text { Open-label trial of } 30 \mathrm{mg} / \text { day } \\
\text { for } 6 \text { months }\end{array}$ & 30 & Safety & $\begin{array}{l}\text { Change in slope of ALSFRS-R } \\
\text { pre to post-treatment }\end{array}$ & $\begin{array}{l}\text { Safe and well tolerated at this dose; } \\
\text { no significant change in ALSFRS-R }\end{array}$ \\
\hline $\begin{array}{l}\text { Open-label dose escalation trial } \\
\text { up to } 300 \mathrm{mg} / \text { day }\end{array}$ & 10 & Safety & & $\begin{array}{l}\text { Safe and well tolerated at } \\
\text { high doses }\end{array}$ \\
\hline $\begin{array}{l}\text { Open-label extension } \\
\text { of } 30 \mathrm{mg} \text { vs } 60 \mathrm{mg} / \mathrm{day}\end{array}$ & $10(?)$ & Safety & $\begin{array}{l}\text { Difference in decline } \\
\text { of ALSFRS-R }\end{array}$ & $\begin{array}{l}\text { Safe and well tolerated; no significant } \\
\text { difference in slopes of ALSFRS-R }\end{array}$ \\
\hline $\begin{array}{l}\text { Phase II randomized controlled trial } \\
\text { of three doses for } 12 \text { weeks }\end{array}$ & 102 & $\begin{array}{l}\text { Safety and } \\
\text { pharmacokinetics }\end{array}$ & & $\begin{array}{l}\text { Safe and well tolerated; } \\
\text { linear pharmacokinetics }\end{array}$ \\
\hline Phase II trial of 50 or $300 \mathrm{mg} /$ day & 92 & Safety & ALSFRS-R and survival & $\begin{array}{l}\text { Safe; improvement in a joint } \\
\text { ALSFRS-R-mortality outcome }\end{array}$ \\
\hline Phase III trial of $300 \mathrm{mg} /$ day & 800 & $\begin{array}{l}\text { ALSFRS-R - Survival } \\
\text { joint endpoint }\end{array}$ & $\begin{array}{l}\text { Other functional measures } \\
\text { and safety }\end{array}$ & Ongoing \\
\hline
\end{tabular}

Abbreviation: ALSFRS-R, revised version of the Amyotrophic Lateral Sclerosis Functional Rating Scale. 
small open-label trials, in which placebo effect and other confounders cannot be controlled for and which has low power to detect efficacy, showed that the drug was safe and well tolerated in doses thought high enough to have neuroprotective effects in humans. The drug did not significantly modify the slope of ALSFRS-R nor the forced vital capacity, but there was inadequate power to detect changes in these secondary outcomes. ${ }^{78}$

A subsequent double-blind, placebo-controlled Phase II trial also assessed the safety and tolerability in ALS, with examination of early efficacy as measured by function and mortality. ${ }^{79}$ The trial had two parts: the first randomized 102 patients to three treatment groups (RPPX $50 \mathrm{mg} /$ day, RPPX $150 \mathrm{mg} /$ day, and RPPX $300 \mathrm{mg} /$ day, in two daily doses) and a placebo group. After a 12-week treatment period, 97 remaining subjects underwent a 4-week washout period before the second part of the trial in which 92 patients were randomized to two double-blind treated groups, $50 \mathrm{mg} /$ day or $300 \mathrm{mg} /$ day, for an additional 24 weeks. Among the 10 patients who dropped out between part 1 and part 2 of the trial, three died from ALS and the others discontinued treatment. Seventy-one patients completed both parts of the trial with an equal number in the treated groups of the second part. Overall RPPX was safe and well tolerated. Adverse effects were modest with only dizziness and reversible neutropenia occurring in the higher dosage sample, causing two patients to discontinue therapy. Pharmacokinetic analyses showed linear plasma pharmacokinetics and an elimination half-life of 6.7-8.2 hours. There were no dose-related changes in vital signs, electrocardiography, or laboratory data. There was no interaction between riluzole and RPPX no matter the dosage. The first part of the study showed a nonsignificant reduction of decline in the slope of the ALSFRS-R score that was more apparent at higher doses. Nonresponders to RPPX who were defined by a drop of 6 points or more of the ALSFRS-R score during the 12 weeks of the first phase were inversely proportional in number to the dosage of RPPX with a significant logistic regression between the four groups. The functional impact of RPPX was greater on the fine motor items of the ALSFRS-R scale. There was no effect on respiratory parameters. In part 2, there were 12 deaths (nine in the $50 \mathrm{mg}$ group and three in the $300 \mathrm{mg}$ group) and a total of 17 serious adverse events, most considered unrelated to the medication. The second part of the trial showed a nonsignificant reduction of the rate of the decline of the ALSFRS-R scores for the $300 \mathrm{mg}$ /day group compared to the lower dose group $(P=0.17)$ and a reduction of $68 \%$ in the hazard of mortality in the higher dosage group
(Log-rank test, $P=0.07) .{ }^{79} \mathrm{~A}$ joint-rank test, performed as a prespecified sensitivity analysis, showed a significant benefit in the combined outcome of change in the ALSFRS-R and mortality $(P=0.046)$.

Based on these results, a Phase III trial of RPPX in ALS is ongoing. The objective is to determine whether $150 \mathrm{mg}$ twice daily of RPPX is effective in ALS compared to placebo. Up to 900 patients (with El Escorial possible, laboratory-supported probable, probable or definite ALS) have been enrolled in this randomized, double-blind, placebo-controlled, multicenter trial at sites in the United States, Canada, Australia, and Europe. The primary outcome measure is the effect on the joint mortality-function endpoint used in the Phase II trial. The study is funded by Biogen idec (Weston, MA) and results should be available in 2013 .

\section{Conclusions}

Pramipexole and its $\mathrm{R}(+)$ enantiomer, dexpramipexole (RPPX), appear to exert meaningful neuroprotective properties through actions involving mitochondria. RPPX was selected for study in ALS because of greater tolerability at high doses than PPX due to lower affinity for dopamine receptors. Studies in models of neurodegeneration show that RPPX reduces oxidative stress, excitotoxicity, and apoptosis. Animal studies suggest an effect on survival in ALS, and early phase human trials have indicated adequate safety and tolerability at doses that provide neuroprotection in animals. It is too soon to reach conclusions about efficacy, but RPPX has undergone thorough groundwork investigation: the scientific justification for study in ALS has been established in preclinical studies, and dose selection has been accomplished in early phase human trials. The investigators can be confident that they are proceeding with a drug that is ready for efficacy testing. The Phase III trial was designed with good power to detect a realistic change in an interesting endpoint. This trial should determine clearly what the effect of RPPX is in ALS, and in the process will show whether meaningfully effective treatments can be identified in ALS before the causes of this still mysterious disease are known.

\section{Disclosure}

The authors report no conflicts of interest in this work.

\section{References}

1. Hirtz D, Thurman DJ, Gwinn-Hardy K, Mohamed M, Chaudhuri AR, Zalutsky R. How common are the common neurologic disorders? Neurology. 2007;68:326-337.

2. Annegers JF, Appel S, Lee JR, Perkins P. Incidence and prevalence of amyotrophic lateral sclerosis in Harris County, Texas, 1985-1988. Arch Neurol. 1991;48:589-593. 
3. Beghi E, Millul A, Micheli A, Vitelli E, Logroscino G. Incidence of ALS in Lombardy, Italy. Neurology. 2007;68:141-145.

4. Marin B, Gil J, Preux PM, Funalot B, Couratier P. Incidence of amyotrophic lateral sclerosis in the Limousin region of France, 1997-2007. Amyotroph Lateral Scler. 2009;10:216-220.

5. Alonso A, Logroscino G, Jick SS, Hernan MA. Incidence and lifetime risk of motor neuron disease in the United Kingdom: a population-based study. Eur J Neurol. 2009;16:745-751.

6. Chio A, Mora G, Calvo A, Mazzini L, Bottacchi E, Mutani R. Epidemiology of ALS in Italy: a 10-year prospective population-based study. Neurology. 2009;72:725-731.

7. Ringholz GM, Appel SH, Bradshaw M, Cooke NA, Mosnik DM, Schulz PE. Prevalence and patterns of cognitive impairment in sporadic ALS. Neurology. 2005;65:586-590.

8. Gordon PH, Delgadillo D, Piquard A, et al. The range and clinical impact of cognitive impairment in French patients with ALS: a cross-sectional study of neuropsychological test performance. Amyotroph Lateral Scler. 2011:12:372-378.

9. Blasco H, Guennoc AM, Veyrat-Durebex C, et al. Amyotrophic lateral sclerosis: A hormonal condition? Amyotroph Lateral Scler. 2012. [Epub ahead of print].

10. Gautier G, Verschueren A, Monnier A, Attarian S, Salort-Campana E, Pouget J. ALS with respiratory onset: clinical features and effects of non-invasive ventilation on the prognosis. Amyotroph Lateral Scler. 2010;11:379-382.

11. Ravits JM, La Spada AR. ALS motor phenotype heterogeneity, focality, and spread: deconstructing motor neuron degeneration. Neurology. 2009;73:805-811.

12. Logroscino G, Traynor BJ, Hardiman O, et al. Descriptive epidemiology of amyotrophic lateral sclerosis: new evidence and unsolved issues. J Neurol Neurosurg Psychiatry. 2008;79:6-11.

13. Wijesekera LC, Leigh PN. Amyotrophic lateral sclerosis. Orphanet $J$ Rare Dis. 2009;4:3.

14. Gordon PH, Corcia P, Lacomblez L, et al. Defining survival as an outcome measure in ALS. Arch Neurol. 2009;66:758-761.

15. Traynor BJ, Codd MB, Corr B, Forde C, Frost E, Hardiman O. Amyotrophic lateral sclerosis mimic syndromes: a population based study. Arch Neurol. 2000;57:109-113.

16. Leigh PN, Abrahams S, Al-Chalabi A, et al. The management of motor neurone disease. J Neurol Neurosurg Psychiatry. 2003;74 Suppl 4 iv32-iv47.

17. Brooks BR, Miller RG, Swash M, Munsat TL. El Escorial revisited: revised criteria for the diagnosis of amyotrophic lateral sclerosis. Amyotroph Lateral Scler Other Motor Neuron Disord. 2000;1: 293-299.

18. De Carvalho M, Dengler R, Eisen A, et al. Electrodiagnostic criteria for diagnosis of ALS. Clin Neurophysiol. 2008;119:497-503.

19. Boekestein WA, Kleine BU, Hageman G, Schelhaas HJ, Zwarts MJ. Sensitivity and specificity of the 'Awaji' electrodiagnostic criteria for amyotrophic lateral sclerosis: retrospective comparison of the Awaji and revised El Escorial criteria for ALS. Amyotroph Lateral Scler. 2010;11:497-501.

20. Nelson LM, McGuire V, Longstreth WT Jr, Matkin C. Populationbased case-control study of amyotrophic lateral sclerosis in western Washington State. I. Cigarette smoking and alcohol consumption. Am J Epidemiol. 2000;151:156-163.

21. Andersen PM, Al-Chalabi A. Clinical genetics of amyotrophic lateral sclerosis: what do we really know? Nat Rev Neurol. 2011;7:603-615.

22. Gurney ME, Pu H, Chiu AY, et al. Motor neuron degeneration in mice that express a human $\mathrm{Cu}, \mathrm{Zn}$ superoxide dismutase mutation. Science. 1994;264:1772-1775.

23. Rowland LP, Shneider NA. Amyotrophic lateral sclerosis. N Engl J Med. 2001;344:1688-1700.

24. Rothstein JD. Current hypotheses for the underlying biology of amyotrophic lateral sclerosis. Ann Neurol. 2009;65 Suppl 1:S3-S9.

25. Gordon PH, Meininger V: How can we improve clinical trials in amyotrophic lateral sclerosis. Nat Rev Neurol. 2011;7:650-654.
26. Johri A, Beal MF. Mitochondrial dysfunction in neurodegenerative diseases. J Pharmacol Exp Ther. June 13, 2012. [Epub ahead of print.]

27. Menzies F, Ince PG, Shaw PJ. Mitochondrial involvement in amyotrophic lateral sclerosis. Neurochem Int. 2002;40:543-551.

28. Afifi AK, Aleu FP, Goodgold J, McKay B. Ultrastructure of atrophic muscle in amyotrophic lateral sclerosis. Neurology. 1966;16:475-481.

29. Bowling AC, Schulz JB, Brown HR Jr, Beal MF. Superoxide dismutase activity, oxidative damage and mitochondrial energy metabolism in familial and sporadic amyotrophic lateral sclerosis. $J$ Neurochem. 1993;61:2322-2325.

30. Cozzolino M, Ferri A, Valle C, Carri MT. Mitochondria and ALS: implications form novel gene and pathways. Mol Cell Neurosci. 2012. [Epub ahead of print].

31. Shi P, Gal J, Kwinter DM, Liu X, Zhu H. Mitochondrial dysfunction in amyotrophic lateral sclerosis. Biochim Biophys Acta. 2010;1892:45-51.

32. Cheah BC, Kiernan M. Dexpramipexole, the $R(+)$ enantiomer of pramipexole, for the potential treatment of amyotrophic lateral sclerosis. I Drugs. 2010;13:911-920.

33. Bensimon G, Lacomblez L, Meininger V. A controlled trial of riluzole in amyotrophic lateral sclerosis. ALS/Riluzole Study Group. $N$ Engl $J$ Med. 1994;330:585-591.

34. Lacomblez L, Bensimon G, Leigh PN, Guillet P, Meininger V. Dose-ranging study of riluzole in amyotrophic lateral sclerosis. Amyotrophic Lateral Sclerosis/Riluzole Study Group II. Lancet. 1996; 347(9013):1425-1431.

35. Morren JA, Galvez-Jimenez N. Current and prospective diseasemodifying therapies for amyotrophic lateral sclerosis. Expert Opin Investig Drugs. 2012;21:297-320.

36. Miller RG, Mitchell JD, Moore DH. Riluzole for amyotrophic lateral sclerosis (ALS)/motor neuron disease (MND). Cochrane Database Syst Rev. 2012;3:CD001447.

37. Rothstein JD. Therapeutic horizons for amyotrophic lateral sclerosis. Curr Opin Neurobiol. 1996;6:679-687.

38. Bozik M, Mather JL, Krammer WG, Gribkoff VK, Ingersholl EW. Safety, tolerability and pharmacokinetics of KNS-760704 (Dexpramipexole) in healthy adult subjects. $J$ Clin Pharmacol. 2011;51:1177-1185.

39. Chio A, Bottacchi E, Buffa C, Mutani R, Mora G. Positive effects of tertiary centres for amyotrophic lateral sclerosis on outcome and use of hospital facilities. J Neurol Neurosurg Psychiatry. 2006;77:948-950.

40. Aboussouan LS, Khan SU, Banerjee M, Arroliga AC, Mitsumoto H. Objective measures of the efficacy of noninvasive positive-pressure ventilation in amyotrophic lateral sclerosis. Muscle Nerve. 2001;24:403-409.

41. Bourke SC, Tomlinson M, Williams TL, Bullock RE, Shaw PJ, Gibson GJ. Effects of non-invasive ventilation on survival and quality of life in patients with amyotrophic lateral sclerosis: a randomised controlled trial. Lancet Neurol. 2006;5:140-147.

42. Chio A, Finocchiaro E, Meineri P, Bottacchi E, Schiffer D. Safety and factors related to survival after percutaneous endoscopic gastrostomy in ALS. ALS Percutaneous Endoscopic Gastrostomy Study Group. Neurology. 1999;53:1123-1125.

43. Rowland LP Dr. Rowland's six levels of hope. ALSD33 ALS-On-Line. ALS Interest Group. ALS Digest \#332. May 27, 1997.

44. Cudkowicz ME, Shefner JM, Schoenfeld DA, et al. Northeast ALS Consortium. A randomized, placebo-controlled trial of topiramate in amyotrophic lateral sclerosis. Neurology. 2003;61:456-464.

45. Miller RG, Moore DH, Gelinas DF, et al. Phase III randomized trial of gabapentin in patients with amyotrophic lateral sclerosis. Neurology. 2001;56:843-848.

46. Fornai F, Longone P, Cafaro L, et al. Lithium delays progression of amyotrophic lateral sclerosis. Proc Natl Acad Sci U S A. 2008;105:2052-2057.

47. Aggarwal SP, Zinman L, Simpson E, et al. Northeast and Canadian Amyotrophic Lateral Sclerosis consortia. Safety and efficacy of lithium in combination with riluzole for treatment of amyotrophic lateral sclerosis: a randomised, double-blind, placebo-controlled trial. Lancet Neurol. 2010;9:481-488. 
48. Chiò A, Borghero G, Calvo A, et al. Lithium carbonate in amyotrophic lateral sclerosis: lack of efficacy in a dose-finding trial. Neurology. 2010;75:619-625.

49. Miller RG, Moore DH, Forshew DA, et al. Phase II screening trial of lithium carbonate in amyotrophic lateral sclerosis: examining a more efficient trial design. Neurology. 2011;77:973-979.

50. Gordon PH, Moore DH, Miller RG, et al. Efficacy of minocycline in patients with amyotrophic lateral sclerosis: a phase III randomised trial. Lancet Neurol. 2007;6:1045-1053.

51. Cudkowicz ME, Shefner JM, Schoenfeld DA, et al. Trial of celecoxib in amyotrophic lateral sclerosis. Ann Neurol. 2006;60:22-31.

52. Meininger V, Bensimon G, Bradley WR, et al. Efficacy and safety of xaliproden in amyotrophic lateral sclerosis: results of two phase III trials. Amyotroph Later Scler. 2004;5:107-117.

53. Meininger V, Drory VE, Leigh PN, Ludolph A, Robberecht W, Silani V. Glatiramer acetate has no impact on disease progression in ALS at $40 \mathrm{mg}$ /day: a double-blind, randomized, multicentre, placebo-controlled trial. Amyotroph Lateral Scler. 2009;10:378-383.

54. Ludolph AC, Bendotti C, Blaugrund E, et al. Guidelines for preclinical animal research in ALS/MND: A consensus meeting. Amyotroph Lateral Scler. 2010;11:38-45.

55. Cheung YK, Gordon PH, Levin B. Selecting promising ALS therapies in clinical trials. Neurology. 2006;67:1748-1751.

56. Gordon PH, Cheung YK, Levin B, et al. A novel, efficient, randomized selection trial comparing combinations of drug therapy for ALS. Amyotroph Lateral Scler. 2008;9:212-222.

57. Levy G, Kaufmann P, Buchsbaum R, et al. A two-stage design for a phase II clinical trial of coenzyme Q10 in ALS. Neurology. 2006; 66:660-663.

58. Albrecht S, Buerger E. Potential neuroprotection mechanisms in PD: focus on dopamine agonist pramipexole. Curr Med Res Opin. 2009;25:2977-2987.

59. Shannon KM, Bennett JP Jr, Friedman JH. Efficacy of pramipexole, a novel dopamine agonist, as monotherapy in mild to moderate Parkinson's disease. The Pramipexole Study Group. Neurology. 1997;49:724-728.

60. Kushida CA. Pramipexole for the treatment of restless legs syndrome. Expert Opin Pharmacother. 2006;7:441-451.

61. Wahl F, Renou E, Mary V, Stutzmann JM. Riluzole reduces brain lesions and improves neurological function in rats after a traumatic brain injury. Brain Res. 1997;756:247-255.

62. Sethy VH, Wu H, Oostveen JA, Hall ED. Neuroprotective effects of the dopamine agonists pramipexole and bromocriptine in 3-acetylpyridinetreated rats. Brain Res. 1997;754:181-186.

63. Cassarino DS, Fall CP, Smith TS, Bennett JP Jr. Pramipexole reduces reactive oxygen species production in vivo and in vitro and inhibits the mitochondrial permeability transition produced by the parkinsonian neurotoxin methylpyridinium ion. J Neurochem. 1998;71:295-301.

64. Sayeed I, Parvez S, Winkler-Stuck K, et al. Patch clamp reveals powerful blockade of the mitochondrial permeability transition pore by the D2-receptor agonist pramipexole. FASEB J. 2006;20: $556-558$.
65. Izumi Y, Sawada H, Yamamoto N, Kume T, Katsuki H, Shimohama S, Akaike A. Novel neuroprotective mechanisms of pramipexole, an antiParkinson drug, against endogenous dopamine-mediated excitotoxicity. Eur J Pharmacol. 2007;557:132-140.

66. Iravani MM, Sadeghian M, Leung CC, et al. Continuous subcutaneous infusion of pramipexole protects against lipopolysaccharide-induced dopaminergic cell death without affecting the inflammatory response. Exp Neurol. 2008;212:522-531.

67. Hall ED, Andrus PK, Oostveen JA, Althaus JS, VonVoigtlander PF. Neuroprotective effects of the dopamine D2/D3 agonist pramipexole against postischemic or methamphetamine-induced degeneration of nigrostriatal neurons. Brain Res. 1996;742:80-88.

68. Anderson DW, Neavin T, Smith JA, Schneider JS. Neuroprotective effects of pramipexole in young and aged MPTP-treated mice. Brain Res. 2001;905:44-53.

69. Fujita Y, Izawa Y, Ali N, et al. Pramipexole protects against H2O2induced PC12 cell death. Naunyn Schmiedebergs Arch Pharmacol. 2006;372:257-266.

70. Pattee GL, Post GR, Bennett JP. Reduction of oxidative stress in amyotrophic lateral sclerosis following pramipexole treatment. Amyotroph Lateral Scler Other Motor Neuron Disord. 2003;4:90-95.

71. Gribkoff FK, Bozik ME. KNS-760704 [(6R)-4,5,6,7-tetrahydro-N6propyl-2, 6-benzothiazole-diamine dihydrochloride monohydrate] for the treatment of amyotrophic lateral sclerosis. CNS Neurosci Ther. 2008;1:215-226.

72. Gu M, Iravani MM, Cooper JM, King D, Jenner P, Schapira AH. Pramipexole protects against apoptotic cell death by non-dopaminergic mechanisms. J Neurochem. 2004;91:1075-1081.

73. Ferrari-Toninelli G, Maccarinelli G, Uberti D, Buerger E, Memo M. Mitochondria-targeted antioxidant effects of S(-) and $\mathrm{R}(+)$ pramipexole. BMC Pharmacol. 2010;10:2.

74. Abramova NA, Cassarino DS, Khan SM, Painter TW, Bennett JP Jr. Inhibition by $\mathrm{R}(+)$ or $\mathrm{S}(-)$ pramipexole of caspase activation and cell death induced by methylpyridinium ion or beta amyloid peptide in SH-SY5Y neuroblastoma. J Neurosci Res. 2002;67:494-500.

75. Danzeisen R, Schwalenstoecker B, Gillardon F, et al. Targeted antioxidative and neuroprotective properties of the dopamine agonist pramipexole and its nondopaminergic enantiomer SND919CL2x [(+)2-amino-4,5,6,7-tetrahydro-6-Lpropylamino-benzathiazole dihydrochloride]. J Pharmacol Exp Ther. 2006;316:189-199.

76. Frantz SW, Demady DR, Dalton JA, et al. Gottingen minipigs as the nonrodent species in the IND for KNS-760704. Int J Toxicol. 2010;29: 1 Abs P17.

77. Alavian KN, Dworetzky SI, Bonanni L, et al. Effects of dexpramipexole on brain mitochondrial conductances and cellular bioenergetics efficiency. Brain Res. 2012;1446:1-11.

78. Wang H, Larriviere KS, Keller KE, et al. R+ pramipexole as a mitochondrially focused neuroprotectant: initial early phase studies in ALS. Amyotroph Lateral Scler. 2008;9:50-58.

79. Cudkowicz M, Bozik ME, Ingersoll EW, et al. The effects of dexpramipexole (KNS-760704) in individuals with amyotrophic lateral sclerosis. Nat Med. 2011;17:1652-1657.
Therapeutics and Clinical Risk Management

\section{Publish your work in this journal}

Therapeutics and Clinical Risk Management is an international, peerreviewed journal of clinical therapeutics and risk management, focusing on concise rapid reporting of clinical studies in all therapeutic areas, outcomes, safety, and programs for the effective, safe, and sustained use of medicines. This journal is indexed on PubMed Central, CAS,
Dovepress

EMBase, Scopus and the Elsevier Bibliographic databases. The manuscript management system is completely online and includes a very quick and fair peer-review system, which is all easy to use. Visit http://www.dovepress.com/testimonials.php to read real quotes from published authors. 